\title{
A representação na arquivística contemporânea ${ }^{1}$
}

\author{
Natália Bolfarini Tognoli \\ nataliatognoli@marilia.unesp.br
}

Universidade Estadual Paulista (UNESP)

\begin{abstract}
Resumo: $\mathrm{O}$ arranjo e a descrição dos documentos de arquivo podem ser considerados os dois processos nucleares da teoria e da prática arquivística que compartilham o mesmo objetivo: representar o conhecimento arquivístico. Esta representação está baseada fundamentalmente na aplicação do princípio da proveniência e no conceito de fundo documental. O presente artigo busca discutir especificamente a descrição arquivística em face das mudanças e propostas de uma abordagem pós-moderna da disciplina que propõe o conceito de fundo e o princípio da proveniência como norteadores conceituais e não como entidades físicas - como até o momento se supunha - no processo de representação. Para tanto, é feita uma revisão de literatura, por meio de um estudo exploratório, teórico e documental nos principais periódicos internacionais e nacionais da área da Arquivologia para apresentar as perspectivas teóricas dos estudos canadenses e australianos que se apresentam na vanguarda do movimento pósmoderno, discutindo as bases teóricas da Arquivística Moderna, face à realidade dinâmica da produção documental contemporânea. Ao final, conclui-se que a abordagem pós-moderna parece ser a mais capacitada para lidar com as questões contemporâneas, uma vez que vai mais a fundo nas questões sobre a representação arquivística e sua relação entre o arquivista, o contexto de criação dos documentos e o usuário.
\end{abstract}

Palavras-chave: fundo de arquivo; princípio da proveniência; descrição

Abstract: The arrangement and description of archival materials are the nuclear processes of Archival Science that share a common purpose: to represent the archival knowledge. This representation is fundamentally based on the application of the principle of provenance and on the concept of fonds. This paper aims to discuss de archival description facing the changes and ideas of an archival postmodern approach that proposes the concept of fonds and the principle of provenance as conceptual abstraction rather than a physical entity in the representation process. In that sense, it is presented here the theoretical perspectives of Canadian and Australian studies, discussing the theoretical basis of Modern Archival Science, facing the dynamic reality of contemporary record creation.

Keywords: fonds; principle of provenance; description.

\footnotetext{
${ }^{1}$ Destaca-se, aqui, que o presente trabalho é a junção de dois artigos publicados pela autora anteriormente, respectivamente no 12th Internacional ISKO Conference, em Bangalore (2012) e no XIII Encontro Nacional de Pesquisa em Ciência da Informação - ENANCIB, no Rio de Janeiro (2012).
} 


\section{INTRODUÇÃO}

Este artigo busca discutir, sob uma perspectiva teórica, a representação arquivística mais especificamente, a descrição arquivística - em face das mudanças e propostas de uma abordagem pós-moderna, com o objetivo de ilustrar os desafios enfrentados pela Arquivística Contemporânea em um novo contexto de produção, organização e representação dos documentos arquivísticos.

São colocados em análise o princípio da proveniência e o conceito de fundo de arquivo, bem como suas aplicações no processo de descrição documental. A escolha pelo estudo dos termos se justifica, uma vez que ambos são constantemente (re) discutidos pela Arquivística pós-moderna, sofrendo grandes alterações no atual contexto de produção e organização do conhecimento arquivístico.

Para tanto, realizou-se um estudo exploratório, teórico e documental a partir das normas de descrição arquivística, e dos principais periódicos de Arquivologia, notadamente aqueles publicados na América do Norte - Archivaria e Archival Science - que nas últimas décadas representam um espaço privilegiado de discussão acerca dos desafios apresentados à disciplina no século XXI.

\section{CONTEXTUALIZANDO A REPRESENTAÇÃO NA ARQUIVÍSTICA MODERNA: O NASCIMENTO DO CONCEITO DE FUNDO E O PAPEL DO ARQUIVISTA}

Desde sua emergência enquanto disciplina, no século XIX, notadamente a partir da publicação do Manual de Arranjo e descrição de arquivos (Handleiding vor het ordenen em bescheijven van archieven), em 1889, pelo trio holandês Muller, Feith e Fruin, a Arquivística tem o arranjo e a descrição dos documentos de arquivo como processos complementares e nucleares de sua teoria e prática, com o objetivo de classificar, ordenar, descrever e fornecer acesso aos documentos. Estes processos têm objetivos específicos, dividindo um objetivo em comum: representar o conhecimento arquivístico ${ }^{2}$.

O princípio da proveniência (respect des fonds), promulgado em 1841, em decorrência da necessidade de solucionar os problemas causados pela organização temática adotada pelos Arquivos Nacionais franceses, após a Revolução Francesa, é considerado o norteador dos processos de representação na Arquivística e, talvez, o método mais seguro para preservar a

\footnotetext{
${ }^{2}$ Para fins de esclarecimento, a autora entende conhecimento arquivístico enquanto o conjunto de informações orgânicas e registradas que compõem um fundo de arquivo.
} 
integridade dos conjuntos documentais produzidos por uma pessoa ou instituição. Segundo Duchein (1983, p. 64, tradução nossa) o princípio consiste em

[...] agrupar, sem misturar a outros, os arquivos (documentos de qualquer natureza) provenientes de uma administração, de um estabelecimento ou de uma pessoa física ou jurídica determinada: o que se chama de fundo de arquivo dessa administração, desse estabelecimento ou dessa pessoa.

A formulação francesa do princípio conta com duas dimensões: interna e externa. A primeira consiste na definição geral do princípio, como explicita Duchein acima, ou seja, em manter os documentos agrupados por seu órgão produtor ou acumulador, enquanto a segunda diz respeito à organicidade dos documentos, à sua ordem original, ou seja, "à observância do fluxo natural e orgânico com que foram produzidos" (BELLOTTO, 2004, p. 131).

Devido à importância atribuída à sua comprovada efetividade, o princípio foi rapidamente adotado por outros países, que incorporaram às suas práticas e teoria a classificação por fundos, dando ao princípio e ao conceito de fundo uma terminologia, ora igual, ora diferente - daquela atribuída pelos franceses - em seus respectivos idiomas. Como exemplo, tem-se a Alemanha com o Provenienzprinzip, que, assim como o termo francês, engloba na mesma terminologia as duas dimensões do princípio e a Inglaterra com Provenance e Sanctity of orignal order, que divide o princípio em dois.

Neste contexto, a partir da enunciação do princípio da proveniência e do conceito de fundo, o trabalho do arquivista moderno passa a ser livre de interpretações, uma vez que não há outra maneira de ver o documento, que não por meio das relações que este estabelece com seu produtor. Desjardins (apud DUCHEIN 1983, p.66) chegou a afirmar que em qualquer outra classificação que não por fundo, corria-se o grande risco de não saber encontrar um documento.

A descrição, enquanto o segundo processo dentro da representação do conhecimento arquivístico, exerce a função de informar acerca do conteúdo dos documentos e de seus elementos formais, com o objetivo maior de fornecer acesso às informações contidas nos fundos, grupos, séries ou peça documental. Segundo Heredia Herrera (1991, p. 300)

[...] a descrição é a análise realizada pelo arquivista sobre os fundos e os documentos de arquivo agrupados natural ou artificialmente, com o objetivo de sintetizar e condensar a informação neles contida para oferecê-la aos interessados [...] ela é a ponte que comunica o documento com os usuários. $\mathrm{Na}$ cabeceira da ponte está o arquivista que realiza uma tarefa de análise que supõe identificação, leitura, resumo e indicação que transmite ao usuário para que este inicie a recuperação em sentido inverso a partir dos índices. 
Pode-se dizer que descrever é um processo que permite ao arquivista representar - no sentido mais denotativo do termo - todo o conhecimento que é mantido em seu arquivo. Para Rodrigues (2003, p. 217) a descrição é uma função-chave no que diz respeito à representação das informações arquivísticas e na possibilidade de acesso a elas. Esta representação vai além do documento, perpassando suas funções e seus órgãos produtores. Neste sentido, o princípio de respeito aos fundos exerce, mais uma vez, um papel central no estabelecimento dos níveis que serão descritos.

No entanto, apesar dos avanços na teoria e prática arquivística, notadamente nos processos de classificação e descrição dos documentos de arquivo, após a publicação do Manual dos Holandeses, ao longo do século XX, o papel do arquivista ainda estava limitado ao de um simples guardião dos documentos, cuja tarefa era proteger a integridade dos fundos e a imparcialidade e autenticidade dos documentos de "valor arquivístico", ou seja, aqueles que já haviam sido avaliados pelos criadores. Tal visão ganhou fôlego, principalmente, com a publicação de A Manual for Archival Administration, em 1922, por Sir Hilary Jenkinson que defendia que o papel do arquivista no arranjo e na descrição do conhecimento deveria limitarse em revelar o sentido e o significado explícitos no documento e à transcrição do mesmo quando este era requerido pelos pesquisadores.

Consequentemente, a representação do conhecimento arquivístico também estava restrita ao significado imediato e estático do que estava registrado, àquilo que poderia ser lido diretamente no documento, resultando em guias, inventários e catálogos baseados em princípios de descrição cujo foco era o conteúdo documento.

\section{A REPRESENTAÇÃO NA ARQUIVÍSTICA CONTEMPORÂNEA: a ruptura do conceito de fundo e o papel do arquivista}

No final da década de 1980, uma mudança de paradigma é anunciada na Arquivística, quando Hugh Taylor admite a obsolescência dos princípios e métodos arquivísticos promulgados no século anterior, caracterizando o final do século XX como um período de revolução científica na área, notadamente após o aparecimento das novas formas de produção de documentos e de novas tecnologias de informação. A disciplina é, então, convidada a repensar suas bases teóricas e práticas fundadas no século XIX para que pudesse dar conta da produção, organização e descrição do conhecimento arquivístico contemporâneo, dando origem à Arquivística Pós-Moderna, que busca "desnaturalizar" o que a Arquivística moderna até então assumira como natural, normal e racional. 
Uma vez que tudo é social e culturalmente construído no mundo pós-moderno, desconstruir e reformular parecem ser a melhor forma de refletir a diversidade na produção e organização do conhecimento arquivístico contemporâneo. A partir desta perspectiva, as definições e os processos centrais da Arquivística são colocados em discussão e entram em debate o conceito de documento de arquivo e os processos usados para criá-lo, organizá-lo e descrevê-lo no século XXI.

Neste contexto, o documento de arquivo, uma vez entendido como um subproduto inocente, neutro e imparcial de uma atividade - características propostas por Jenkinson - é agora entendido como uma entidade social e culturalmente construída, um símbolo moldado pelo autor para um objetivo específico, longe de ser um subproduto inocente e imparcial. Consequentemente, a organização e a descrição desse conhecimento não devem mais ser estudadas como processos neutros e livres de influências funcionais e sociais.

Especificamente, no tocante à representação arquivística, o final da década de 1980 registra também um interesse por parte de alguns arquivistas norte-americanos em revisar o processo de descrição dos documentos, que até aquele momento limitava-se ao conteúdo imediato fornecido na análise documental. Dentre esses estudos destaca-se o de David Bearman (1999) que advoga em favor de uma mudança da descrição para a documentação, utilizando a expressão "documenting documentation", cuja diferença reside, basicamente, na passagem dos estudos do documento, enquanto a principal fonte de informação, para a atividade da instituição geradora do documento enquanto o objeto a ser documentado.

\begin{abstract}
A descrição foca-se nos documentos enquanto um objeto a ser descrito e enquanto a principal fonte de informação. Ela procura caracterizar os materiais de arquivo construindo documentos ou unidades substitutos. Esses substitutos, chamados de catálogos, instrumentos de pesquisa ou inventários de arquivo representam uma 'unidade do material' ou documentos físicos. Nos sistemas de descrição arquivística esses substitutos serão o tipo de documento essencial ou o arquivo central aos quais todos os índices se referem. [...] A documentação foca-se na atividade da instituição geradora dos documentos - ou na atividade do criador dos documentos no caso de manuscritos - enquanto o objeto a ser documentado e como a fonte preferencial de informação. Ela procura capturar os dados sobre a relação entre a atividade e o documento criado ou recebido naquela atividade, que é necessária para que o documento sirva como prova. [...] nos sistemas de informação documentária tanto a atividade quanto a documentação dos materiais documentários serão fisicamente representadas em vários arquivos; haverá ligações representando as relações entre eles (BEARMAN, 1999, p. 34, tradução nossa).
\end{abstract}

O que Bearman propõe é uma descrição (documentação, em seus termos) anterior à criação dos documentos. Segundo sua abordagem, o arquivista deve entender as atividades, os procedimentos e os sistemas de informação que darão origem ao documento para poder 
identificá-lo antes mesmo de ser criado, uma vez que seu valor de prova e seu conteúdo informativo são essencialmente pré-determinados.

Quando a documentação dos conteúdos organizacionais, funcionais e sistêmicos de criação dos documentos acontece no momento de criação e é usado por pessoas que estão intimamente familiarizadas com a organização e com seus processos informacionais, é provável que a documentação seja intelectualmente mais válida e mais fácil de obter do que em um processo de descrição post hoc. É também mais provável que satisfaça as necessidades dos usuários, que são, primeiramente, a equipe da organização que busca os documentos associados às atividades e responsabilidades das organizações onde trabalha (BEARMAN, 1999, p. 39, tradução nossa).

Compreende-se, portanto, que o foco da documentação, em substituição à descrição, proposto por Bearman (1999) é a representação (1) das características da atividade humana que irão resultar em documentos; (2) das funções que essas atividades pretendem realizar e; (3) dos sistemas de informação que produzem os documentos.

No entanto, em que pese a importância das considerações de Bearman, deve-se levar em conta a realidade específica de cada arquivo e, principalmente de cada país. A interferência do arquivista no momento da produção é constantemente discutida na literatura da área, como parte da gestão documental, porém sua participação não é comumente aceita quando parte-se para a prática. Não é raro encontrarmos casos, nos quais o arquivista encontra barreiras para realizar o trabalho de gestão, principalmente no momento de estabelecer as diretrizes para uma racionalização ou formalização da produção documental. Essa realidade é resultado de uma cultura organizacional fechada que não está "preparada" para mudanças, muito menos para ter um profissional de outra área, dizendo o que deve e o que não deve ser registrado.

A proposta de Bearman insere-se em um contexto maior, no qual a Arquivística pósmoderna apresenta novas ideias e outras "soluções" para os problemas enfrentados pela representação do conhecimento arquivístico no contexto atual.

Especificamente, no que tange à representação desse conhecimento, é importante destacar o papel do arquivista enquanto um agente ativo na construção da memória e na atribuição de sentidos, uma vez que o significado do documento deve ser agora, constantemente renovado à medida que cada usuário o utiliza com objetivos diferentes. $\mathrm{A}$ partir da perspectiva da Arquivística Pós-Moderna, o significado do documento muda ao longo do tempo de acordo com os usos que cada pessoa pretender fazer dele. Como destacam Duffy e Harris (2002, p. 265, tradução nossa)

[...] os documentos estão sempre sendo feitos, 'suas' histórias nunca terminam, e as histórias daqueles que são convencionalmente chamados de criadores de documentos, gerenciadores, arquivistas, e usuários, são partes 
de histórias maiores compreensíveis apenas em contextos maiores da sociedade e em constante mudança.

A Arquivística desloca, portanto, seu foco do conjunto de documentos para os contextos social, organizacional e funcional em constante criação. Consequentemente, o ato de representar deve seguir um fluxo dinâmico e os arquivistas devem "começar a pensar menos em termos de processos de arranjo e descrição estáticos e definitivos, e mais em termos de descrições e arranjos contínuos, relativos e fluidos, como processos representativos sempre em andamento" (YAKEL, 2003).

Em face das novas perspectivas dos processos de criação e organização do conhecimento arquivístico, o princípio da proveniência e o conceito de fundo - cuja importância e precisão raramente são contestadas - também passam por mudanças que deverão estar refletidas no momento da representação dos documentos de arquivo.

Duffy e Harris (2002, p. 268, tradução nossa) destacam que

[...] nas burocracias modernas, é comum que o mesmo documento seja criado, acumulado, e usado por numerosos e diferentes órgãos sucessivamente ou em paralelo. Documentos emanados de atividades administrativas são usados para apoiar e realizar outras atividades administrativas. Além disso, séries de documentos são deslocadas do controle e custódia de uma organização para outra. Essa realidade tem levado vários arquivistas a sugerir que os aspectos multifacetados da proveniência são desgastados quando a prática arquivística dita a criação de fundos em nível de descrição e credita a criação do documento (e portanto, sua proveniência) a apenas um indivíduo ou organização.

Neste aspecto, o princípio da proveniência assume um caráter múltiplo em um contexto de produção contemporânea, onde um documento é produzido com o objetivo de apoiar várias atividades, passando por vários momentos de criação, em órgãos diferentes. Há, portanto, a necessidade de ligar o documento a todos os seus contextos, focando em todas as relações que foram estabelecidas entre ele e os órgãos que o utilizaram, para que sua natureza multifacetada possa ser inteiramente representada.

Logo, o estudo da proveniência como um pressuposto para a representação arquivística encontra fulcro não apenas na compreensão do conteúdo imediato do documento, mas também em sua relação com os criadores, as funções e os sistemas de gerenciamento e manutenção. Mais uma vez, todos os contextos devem ser representados no momento da classificação/arranjo e descrição do conhecimento arquivístico.

No entanto, há de se ter em mente que tanto o princípio da proveniência, quanto o conceito de fundo devem ser analisados enquanto algo conceitual e dinâmico, e não enquanto 
uma entidade física. Ou seja, o estabelecimento de um fundo documental deve fornecer parâmetros para uma representação adequada em um nível intelectual.

Durante as últimas décadas a aplicação do conceito de fundo de arquivo na descrição arquivística tem enfrentado um problema prático que advém, segundo Cook (1993, p. 24) de enxergá-lo exclusivamente enquanto uma entidade física ao invés de um princípio conceitual. Essa visão reflete, de acordo com Bearman (1999), uma tradição de catalogação descritiva guiada pelo documento, em oposição a uma abordagem de gerenciamento de dados guiada pelo contexto do ciclo documental, entendendo o princípio da proveniência enquanto virtual e dinâmico que rege as atividades práticas e o estabelecimento de séries físicas.

Na visão de ambos os autores é fundamental que a descrição arquivística tenha seu foco na conjunção do contexto da atividade e do sistema de informação na organização e criação de documentos. Essa conjunção pode acontecer no nível de fundo "contanto que o fundo esteja realmente apresentado como uma conjunção das funções dos criadores e das atividades de um lado e como a conjunção dos documentos e dos sistemas de informação - os verdadeiros produtos que procederam daquelas funções e atividades - ou no nível das séries (COOK, 1993, p. 28, grifo nosso). Ainda segundo o autor,

[...] onde há uma correspondência direta entre a noção abstrata das atividades do criador e a realidade concreta e física que origina os documentos, não há problema em definir e descrever essa conjunção e, portanto, em delimitar e definir fundos [...] Onde não há essa correspondência direta entre o conceitual e o físico, entre criador e documento, como é o caso da maioria das organizações e dos documentos eletrônicos, o arquivista encontra imediatamente problemas práticos ao aplicar o conceito de fundo na realidade de trabalho (COOK, 1993, p. 28, tradução nossa).

Neste sentido, segundo a abordagem pós-moderna, o estabelecimento de fundos, enquanto o nível físico máximo na representação, só terá um efeito positivo quando se tratar se pequenas organizações.

A abordagem pós-moderna e seus autores defendem, portanto, a abolição do fundo do sistema de classificação de arquivos, uma vez que ele não permite que o arquivista trabalhe com as múltiplas proveniências dos documentos. Como eles entendem o documento enquanto um continuum, estabelecer um único criador ou fundo seria muito limitante. Para McKemmish (1998, p. 192) a reconstrução física de um conjunto de documentos em fundo, ao fornecer a visão de apenas uma realidade múltipla, obscurece ou oblitera outras visões.

Na concepção de Cook (1993, p. 31) se o conceito de fundo está ligado principalmente ao criador, obscurecer criações múltiplas e complexas ao atribuir os documentos física e 
intelectualmente a fundos únicos, durante o arranjo e descrição, distorce a proveniência e, portanto, mina o propósito central da descrição.

Para compreender o conceito de fundo enquanto um guia virtual e conceitual - ao invés de uma categoria física - alguns autores (SCOTT, 1966; COOK, 1993; MCKEMMISH, 1998; HORSMAN, 2002; DUFF \& HARRIS, 2002; YEO, 2012) propõem a série como a primeira categoria a ser considerada no arranjo físico dos arquivos.

A proposta dos autores pós-modernos encontra fundamento na medida em que considera a série como o real objeto dos estudos da classificação e descrição, uma vez que os grupos de documentos da mesma natureza são palpáveis e concretos.

\begin{abstract}
Tanto o fundo quanto suas primeiras divisões - grupos ou seções e subgrupos ou subseções (se houver) - são, na verdade, nomes que correspondem ao órgão maior e suas subordinações, designando, no arquivo, aglutinações de documentos. Isso significa que as séries e subséries é que são a realidade fundamental e concreta com a qual o arquivista vai trabalhar formalmente (BELLOTTO, 2004, p. 152).
\end{abstract}

Essa abordagem, baseada nos contextos funcional e estrutural propostos pela Arquivística pós-moderna encontra fulcro, dentre outros, nos sistemas de descrição australianos que têm investigado essas relações contextuais ao longo das últimas décadas entendendo os documentos de arquivo como organismos dinâmicos e virtuais em constante evolução.

O sistema de descrição dos Arquivos Nacionais da Austrália desde a publicação do artigo de Peter Scott em 1966, ignora o conceito de fundo descrevendo as séries de documentos como o principal nível de classificação e o item documental como o segundo nível. Segundo Scott, há alguns problemas apresentados na aplicação do conceito de fundo nos arquivos (por exemplo, quando um fundo é criado a partir de documentos transferidos de outro órgão o risco é que eles possam perder a ordem original; ou quando séries parecidas são criadas por órgãos diferentes na mesma organização) que só podem ser solucionados com a aplicação das séries como categoria principal.

No que tange à representação arquivística, considerar a série enquanto a categoria física principal nos sistemas de classificação permite ao arquivista

[...] descrever séries de documentos em sua totalidade e ligar as descrições dos documentos a todas as entidades contextuais que criaram, acumularam, usaram, controlaram, detiveram, ou transferiram os documentos das séries. Este sistema enfatiza a importância de ligar uma entidade documental às suas várias entidades contextuais e salienta a importância de inter-relações (DUFF; HARRIS, 2002, p. 268, tradução nossa). 
A própria definição do conceito de fundo enquanto um "conjunto" de documentos produzidos e/ou recebidos por um mesmo órgão, proposta pelas normas de descrição, encontra um problema prático. Segundo Horsman (2002) se um repositório arquivístico manter apenas os documentos permanentes de uma instituição e os correntes permanecerem com o produtor parece errado usar o termo fundo para se referir apenas aos documentos permanentes, uma vez que eles não compõe o "todo dos documentos - the whole of the records" que constitui um fundo.

\begin{abstract}
Os métodos arquivísticos centrados no respeito aos fundos, portanto, servem à custódia e à conveniência do arquivista em agrupamento arrumados e bem definidos. Eles não servem necessariamente aos usuários ou pesquisadores. É claro que os arquivistas fingem - e eles podem até mesmo acreditar - que a sua conveniência administrativa também serve mais bem ao usuário ao proteger a proveniência. $O$ usuário, no entanto, tem sido seriamente enganado pelos arquivistas e por seus fundos. Os métodos arquivísticos de arranjo e descrição, baseados no respeito aos fundos, apresentam ao usuário um agrupamento monolítico de documentos que, na realidade, nunca existiram em nenhuma hora, fora dos arquivos. A proveniência é, portanto, minada: o todo conceitual baseado no funcionamento dos procedimentos administrativos foi obscurecido por um resto físico que sobrevive como fundo de arquivo (HORSMAN, 2002, p.22, tradução nossa).
\end{abstract}

Verifica-se, portanto que, para Horsman, a aplicação do conceito de fundo, enquanto uma entidade física funciona como algo completamente artificial, no sentido de que o arquivista "monta" um arquivo que originalmente não existiria enquanto um conjunto de documentos produzidos por uma mesma pessoa em função de uma mesma atividade. Tal pensamento encontra fulcro também nas ideias de Yeo (2012) sobre as definições rígidas de artificial e orgânico no conceito de fundo de arquivo que, segundo ele são insustentáveis.

As distinções rígidas entre "orgânico" e "artificial" são insuportáveis; nós temos um continuum, de conjuntos compostos inteiramente de documentos gerados durante a vida ou trabalho de um indivíduo àqueles cujos conteúdos foram totalmente adquiridos a partir de fontes externas [...] Ultimamente qualquer agregação que resulte de uma ação humana consciente é uma criação artificial (YEO, 2012, p. 52, tradução nossa).

Não é por acaso que a abordagem pós-moderna encontra, dentre os autores modernos, uma forte oposição. Os autores Terry Eastwood (2002) e Heather MacNeil (1992) estão entre os que não concordam com o abandono do conceito de fundo, defendendo que não há outra proveniência além do órgão que criou o documento. Para estes autores o conceito de fundo é perfeitamente válido e seu abandono enquanto norteador físico traria sérios problemas para a organização arquivística. 
Embora essas abordagens discordem no que tange à questão da proveniência, ambas buscam o mesmo objetivo: representar - organizar e descrever - o contexto e o valor de prova dos documentos de arquivo.

O poder de descrever é o poder de fazer e refazer os documentos e determinar como eles serão usados e refeitos no futuro. Cada história que contamos sobre nossos documentos, cada descrição que compilamos, muda o significado dos documentos e os recria. Essas visões diferentes da proveniência afetam significativamente a arquitetura descritiva proposta por quem as defende. Igualmente influentes são suas certezas sobre o que é a descrição arquivística, quando ela nasce e seu propósito (DUFF; HARRIS, 2002, p. 271, tradução nossa).

A conexão entre o documento e seu contexto é um processo intelectual que é materializado por meio dos instrumentos de pesquisa resultados dos processos de representação do conhecimento arquivístico e entendidos como uma ponte entre o usuário e o documento. Para Cook (2001), o processo de descrição deve refletir a história do documento que está em constante mudança, uma vez que quando um usuário acessa o documento novas representações são criadas a partir dos novos usos e interpretações.

Neste contexto, a abordagem pós-moderna baseada na descrição por sistemas de séries advoga que os instrumentos de pesquisa devem ser constantemente recriados e atualizados para refletir e representar realidades complexas e dinâmicas em processos em constante mudança, indo de encontro com a abordagem baseada na descrição por fundos, que representa objetos estáticos e que, consequentemente, produz instrumentos de pesquisa estáticos, como é o caso dos padrões internacionais de descrição e decodificação de instrumentos de pesquisa que sustentam o processo de representação na Arquivística moderna.

Tais instrumentos como a ISAD (G) - General International Standard Archival Description - a ISAAR (CPF) - International Standard Archival Authority Record for Corporate Bodies - a EAD - Encoded Archival Description -, a RAD - Canadian Rules for Archival Description, entre outros, apresentam um desafio ao profissional da informação em um contexto onde a desconstrução de rotinas padronizadas se faz necessária na medida em que os processos de produção, organização e representação dos documentos adquirem um status dinâmico na disciplina, indo contra a posição estática e neutra observada até agora.

Outro problema apresentado pelas normas é o fato de elas não abrangerem as novas discussões sobre classificação e descrição por séries e itens documentais - embora a RAD apresente algo, ainda que superficialmente, sobre o assunto. Isso demonstra, ainda, um distanciamento da teoria e da prática que parece longe de terminar, uma vez que tais instrumentos não parecem estar comprometidos com a verdadeira realidade dos órgãos 
produtores e acumuladores dos documentos, criando instrumentos estáticos e padronizados para realidades completamente dinâmicas e diferentes.

Além dos problemas com os padrões internacionais para a descrição dos documentos de arquivo, a Arquivística enfrenta uma mudança conceitual, uma vez que seus princípios e definições nem sempre encontram um consenso entre os autores da área. O princípio da proveniência e o conceito de fundo são apenas alguns exemplos dentre os muitos conceitos e termos que são interpretados de maneiras diferentes. Este problema conceitual tem um maior reflexo nos processos de organização e representação uma vez que um conceito ou princípio mal interpretado pode levar o profissional da informação a cometer erros irreparáveis. É por essa razão que é tão importante e urgente discutir essas questões, uma vez que leva a disciplina a uma solidificação em um momento de mudanças e rupturas paradigmáticas diante das novas formas de criação e gerenciamento de documentos.

No entanto, o maior desafio enfrentado hoje pela Arquivística no que tange à representação do conhecimento é fazer o arquivista compreender o sistema complexo de relações entre o documento e seu contexto (ou seja, todas as intenções existentes por trás da criação do documento e da informação que ele leva) para que ele possa mover-se "de um legado monolítico da teoria arquivística passada, da abordagem antiga de uma-coisa-umaentrada" (COOK, 2001, p. 32, tradução nossa).

\section{Considerações finais}

O presente trabalho não busca introduzir uma nova forma de pensar o fundo documental na Arquivística brasileira, muito menos propor uma revolução na representação dos documentos de arquivo. O que se propõe é uma reflexão acerca dos conceitos e dos processos basilares que compõem a Arquivística em face das novas mudanças e ao surgimento de novas realidades e abordagens, com base no estudo da literatura que vem sendo produzida na área.

Países como o Canadá e a Austrália têm tomado a frente das discussões sobre teoria e prática dos arquivos e raras vezes encontram espaço nos estudos arquivísticos do Brasil. Neste sentido, o presente artigo intentou, ainda, trazer as discussões atuais sobre a teoria e a prática da Arquivística internacional, mais especificamente da abordagem pós-moderna que confronta tudo aquilo que até então fora aceito como verdade absoluta pela Arquivística Moderna, amplamente aceita no Brasil e raramente discutida.

Considerando o que foi exposto, é possível concluir que até o presente momento, a abordagem pós-moderna parece ser a mais capacitada para lidar com as questões 
contemporâneas, uma vez que vai mais fundo nas questões sobre a representação arquivística e sua relação entre o arquivista, o contexto de criação dos documentos e o usuário.

Neste sentido, a representação arquivística pós-moderna refletiria, resumidamente, "uma pesquisa sustentada no contexto, pelo arquivista, sobre a história dos documentos e de seus criadores, produzindo descrições em constante mudança, uma vez que a criação dos documentos e a sua própria história custodial nunca terminam" (COOK, 2001, p. 34, tradução nossa).

Portanto, a representação do conhecimento arquivístico não deve mais limitar-se aos padrões de descrição arquivística ou às visões estáticas propostas pelo arquivista e pelo próprio documento. A Arquivística deve estar ciente que a representação do documento de arquivo é continuamente reinventada e reconstruída.

Descrever é como o arquivista faz e refaz o documento. Neste contexto, é seu papel encontrar, dentre as abordagens, um equilíbrio que possa oferecer a melhor representação do documento, aquela que mais bem encaixe no contexto único e particular que ele está descrevendo.

BEARMAN, D. Documenting documentation. Archivaria, 34 (summer), p. 33-49, 1999.

BELLOTTO, H.L. Arquivos permanentes: tratamento documental. 2a ed. Rio de Janeiro: FGV, 2004.

BUREAU OF CANADIAN ARCHIVISTS. Rules for archival description- RAD. Ottawa, 1990.

CONSELHO INTERNACIONAL DE ARQUIVOS. ISAD (G): norma geral internacional de descrição arquivística, adotada pelo Comitê de Normas de Descrição. Estocolmo, Suécia, 19-22 de setembro de 1999. 2. ed. Rio de Janeiro: Arquivo Nacional, 2001.

. ISAAR (CPF): norma internacional de registro de autoridade arquivística para entidades coletivas, pessoas e famílias, adotada pela Comissão ad hoc de Normas de Descrição. Paris, França, 15-20 de novembro de 1995, versão final aprovada pelo CIA. Rio de Janeiro: Arquivo Nacional, 1998.

COOK, T. The concept of the archival fonds in the post-custodial era: theory, problems and solutions. Archivaria, 35 (spring), p. 24-37, 1993

COOK, T. Fashionable Nonsense or professional rebirth: postmodernism and practices of archives. Archivaria, 51 (spring), p. 14-35, 2001

DUCHEIN, M. Theoretical principles and practical problems of respect des fonds in Archival Science. Archivaria, 16 (summer), p. 64-82, 1983. 
DUFF, W.; HARRIS, V. Stories and names: Archival description as narrating records and constructing meanings. Archival Science, n.2, p. 263-285, 2002.

EASTWOOD, T. Putting the parts of the whole together: systematic arrangement of archives. Archivaria, 50 (fall), p. 93-116, 2002.

ENCODED ARCHIVAL DESCRIPTION. Disponível em <http://www.loc.gov/ead/> Acesso em 12 de maio de 2008.

HEREDIA HERRERA, A. Archivística general: teoría y práctica. Sevilla : Disputacíon de Sevilla, 1993.

HORSMAN, P. The last dance of the Phoenix, or the De-rediscovery of the Archival Fonds. Archivaria, 54 (fall), p. 01-23, 2002.

MCKEMMISH, S. Are records ever actual? In: MCKEMMISH, S.; PIGGOT, M (Eds). The records continuum. Clayton: Ancora Press, 1998.

MACNEIL, $\mathrm{H}$. The context is all: describing a fonds and its parts in accordance with the rules for archival description. In: EASTWOOD, T. (ed). The archival fonds: from theory to practice. Ottawa: Bureau of

Canadian Archivists, 1992.

RODRIGUES, G. M. A representação da informação em arquivística: uma abordagem a partir da perspectiva da norma internacional de descrição arquivística. In: RODRIGUES, G.M.; LOPES, I.L. (Org.). Organização e representação do conhecimento na perspectiva da ciência da informação. Brasília: Thesaurus, 2003, v. 2, p. 210-230.

SCOTT, P. The record group concept: a case for abandonment. American Archivist, 29, n. 4, p. 493-504, 1966.

YAKEL, E. Archival Representation. Archival Science, n. 3, p. 1-25, 2003.

YEO, G. The conceptual fonds and the physical collection. Archivaria, n. 73 (spring), p. 43-80, 2012. 